\title{
Litotetothrips Priesner (Thysanoptera, Phlaeothripinae); an Asian genus newly recorded from Australia with two new species and one new combination
}

\author{
LAURENCE A. MOUND ${ }^{1} \&$ DESLEY J. TREE 2 \\ ${ }^{1}$ Australian National Insect Collection CSIRO, PO Box 1700, Canberra, ACT 2601. \\ ”laurence.mound@csiro.au; $\odot$ https://orcid.org/0000-0002-6019-4762 \\ ${ }^{2}$ c/o Queensland Primary Industries Insect Collection (QDPC), Department of Agriculture and Fisheries, Queensland, Ecosciences \\ Precinct, GPO Box 267, Brisbane, Qld, 4001. \\ "=treefamily@bigpond.com; @ https://orcid.org/0000-0002-7704-7750
}

\begin{abstract}
Relationships are discussed among the five genera related to Liothrips in which species have antennal segment VIII long and slender. Litotetothrips is the oldest of these generic names and is used here for three species newly recorded from Australia: L. caledonensis (Bournier) comb.n., L. gallicola sp.n. and L. tareei sp.n.
\end{abstract}

Key words: Liothrips-lineage, Gynaikothrips group, Teuchothrips, Thlibothrips, Gemmathrips, Rosingothrips

\section{Introduction}

The taxonomic identity and relationships of leaf-feeding Phlaeothripinae in the Liothrips/Gynaikothrips group is notoriously confusing (Mound \& Tree 2021b). This group is a major element in the Liothrips-lineage (Mound \& Marullo 1996), and many monotypic genera are involved. Such genera usually differ from members of the worldwide, species-rich genus Liothrips only in some singular autapomorphy (Dang et al. 2014), whereas some larger genera, such as Teuchothrips, are distinguished only on weak, variable character states (Mound 2008). The species described here from Australia involve similar problems in a group of five genera (Athlibothrips, Gemmathrips, Litotetothrips, Rosingothrips and Thlibothrips), members of which have an unusually elongate eighth antennal segment.

Priesner (1929) erected Litotetothrips as a new genus for a species from Taiwan and distinguished it, amongst the Liothrips/Gynaikothrips group, by the long, slender eighth antennal segment. Subsequently, Priesner (1952) erected the genus Thlibothrips for three species described by Karny from Java and Vietnam, together with a subgenus, Athlibothrips with a single species from Vietnam. These two genus-level taxa were both stated to share a similar long eighth antennal segment, as well as the presence of one posterolateral facet on each eye clearly enlarged. However, despite recognising them as members of the Liothrips group, Priesner made no mention of his earlier genus Litotetothrips.

Okajima (1981) recognised Athlibothrips as a separate genus, based on a longer, more pointed mouth cone than that found in species of Thlibothrips. However, he added that "Thlibothrips could well be treated as a gall-forming species group of the genus Litotetothrips". Subsequently, Okajima (2006) distinguished Thlibothrips from Litotetothrips as having the head length more than 1.1 times as long as wide but with the maxillary stylets not retracted into the head as deeply as the postocular setae. He contrasted this to Litotetothrips with the head almost as long as wide, and the stylets retracted to the postocular setae. He also indicated that the species of Litotetothrips do not induce leaf-roll galls in contrast to Thlibothrips species, but he made no mention of Athlibothrips. Moreover, neither of the two new species of Thlibothrips described by Okajima (2006) was described or illustrated as having a posterolateral eye facet unusually large, in contrast to the original description of that genus by Priesner (1952).

Two further monotypic genera, Gemmathrips and Rosingothrips from the Philippines, share with Thlibothrips as described by Priesner the presence of an elongate eighth antennal segment, and the compound eyes each with one 
posterolateral facet enlarged. However, in describing these two genera Reyes (1994) did not discuss the significance of their elongate eighth antennal segment, nor their relationships to the genus Thlibothrips with which they share other character states. The descriptions state erroneously that the number of sense cones on the fourth antennal segment is two in Gemmathrips and four in Rosingothrips, whereas the type specimens of both have three sense cones on the fourth antennal segment.

In a key to Asian Phlaeothripinae genera, Dang et al. (2014) accepted the published generic distinctions, although without studying the Priesner type specimens. However, character states proposed for distinguishing these genera, including ones suggested by Kudo (1975), are not robust when all of the species are considered together. For Thlibothrips, modern descriptions and illustrations are available for only two of the seven listed species (ThripsWiki 2021), but it is clear from the descriptions and illustrations given by Okajima (2006) that both species share many character states with the shorter-headed members of the genus Litotetothrips. Of the three species discussed below, the first conforms to the Thlibothrips diagnosis of Okajima, with the head long and the stylets least retracted. However, this species was found inducing leaf-roll galls, and in contrast to the description of Thlibothrips by Priesner none of the compound eye posterior facets are enlarged.

It is not possible to establish new generic synonymies without study of the original specimens on which Priesner erected Thlibothrips, but it seems probable that the five generic names indicated above all represent a single lineage. In view of the variation in head length, stylet position and eye structure among the available specimens, the three species considered below are included in Litotetothrips, the earliest of the available generic names, and as a result this genus is here recorded from Australia for the first time. It should also be noted that the induction of leaf-roll galls is not necessarily an essential character state of all members of a thrips genus. Some species of Leeuwenia induce remarkable galls (Mound \& Tree 2021a), but other species in this genus are known only from leaves with little or no deformation. Similar variation occurs between species in the Neotropical genus Holopothrips in their effect on leaves (Lindner et al. 2018).

\section{Acknowledgements and abbreviations}

We are grateful to Mark Schutze of the Queensland Primary Industries Insect Collection, Brisbane (QDPC) for organising loans to Canberra of many thrips slides.

The following standard abbreviations are used for setae: po — postocular; am—anteromarginal; aa—anterangular; ml—midlateral; epim—epimeral; pa—posteroangular.

\section{Litotetothrips Priesner}

Litotetothrips Priesner, 1929: 449. Type species L. cinnamomi Priesner (=Gynaikothrips rotundus Moulton), by monotypy.

Ten species are listed in this genus (ThripsWiki 2021), and a key to nine of these is provided by Kudo (1994). Of these nine, Kudo indicates that four species lack fore wing duplicated cilia, and this is also reported for the tenth species that was described from Hainan, China (Feng \& Gou 2004). Considering the described five species in which duplicated wing cilia are present, only L. roberti Kudo (1975) from Japan, Honshu, has the pelta with a pair of campaniform sensilla, although the three species from Australia considered below also share this character state (Figs 4, 5).

Generic diagnosis. Brown macropterous Phlaeothripinae with antennal segment VIII long and slender (Figs 6-8). Head 1.0 to 1.4 times as long as wide; posterior ocelli in contact with eye; compound eyes sometimes with one posterolateral facet enlarged; postocular setae usually shorter than eye; vertex with little sculpture; maxillary stylets usually widely separated, position varying from low in head to retracted almost to postocular setae. Antennae 8-segmented; segment III with one sense cone, IV with 2 or 3 sense cones; VIII long, slender and narrowed to base. Pronotum broad, with little sculpture; notopleural sutures complete or incomplete; am and aa setae minute to small. Metanotum with longitudinally elongate reticulation usually weak anteromedially. Fore tarsi without tooth in both sexes; fore wing broad, some species with many duplicated cilia but other species without duplicated cilia; 2 or 3 sub-basal setae present. Prosternal basantra absent; ferna widely separated; mesopresternum complete, or slender, or reduced to irregular fragments; metathoracic sternopleural sutures absent. Pelta recessed into anterior margin of 
tergite II, shape variable, triangular or with lateral wings; tergites II-VIII each with 2 pairs of sigmoid wing-retaining setae placed rather laterally; tergite IX major setae long; tube about as long as head. Male sternite VIII without pore plate.

\section{Key to Litotetothrips species from Australia}

1. Head 1.3 times as long as wide (Fig. 1); maxillary stylets retracted about half-way to postocular setae ....... gallicola sp.n.

-. $\quad$ Head no more than 1.1 times as long as wide (Fig. 2); maxillary stylets retracted into head to postocular setae . . . . . . . 2

2. Major setae on head and pronotum pale; pronotal am setae acute, 5-15 microns long (Fig. 2); mesopresternum transverse but slender (Fig. 10); one posterolateral facet of eyes enlarged. . . . . . . . . . . . . . . . . . caledonensis Bournier comb.n. Major setae on head and pronotum dark brown; pronotal am setae bluntly capitate and 25 microns long; mesopresternum fully

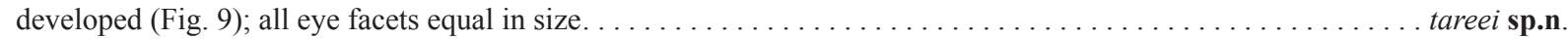

\section{Litotetothrips caledonensis (Bournier) comb.n.}

(Figs 2, 3, 6, 10)

\section{Athlibothrips caledonensis Bournier, 1993: 361}

This species was described from five females and six males taken in rolled leaves of Cordia discolor on New Caledonia, but Bournier also mentioned four females taken from a related species of Cunoniaceae, Pancheria alatanoides. None of these specimens have been re-examined, but the original description and illustration is clear, and the following redescription is based on adult specimens taken from the same host plant, as detailed below.

Female macroptera. Body and legs brown, head and tube darkest, tarsi slightly paler; antennal segments I-II and V-VIII brown, III mainly yellow, IV varying from yellowish brown to brown; fore wings brown at base, then a pale band with distal two-thirds shaded; major setae all pale. Head scarcely longer than wide (Fig. 2), widest just behind eyes, genae slightly narrowed to base without setae; vertex with faint irregular transverse sculpture lines; one or two posterolateral eye facets slightly enlarged; stylets retracted to postocular setae, with maxillary bridge; po setae blunt at apex, median cephalic setae sometimes long. Antennal segment IV with 3 sense cones. Pronotum with a few sculpture lines at anterior and posterior, smooth medially; am setae pointed and usually minute; notopleural sutures almost complete; epim and pa setae weakly capitate. Mesonotal lateral setae small and blunt at apex; metanotal median setae small and acute. Prosternal ferna as wide apart as their diameter (Fig. 10); mesopresternum transverse but slender. Fore wing with 11 duplicated cilia. Pelta broadly triangular, with paired campaniform sensilla (Fig. 3); tergite lateral setae blunt to weakly capitate, setae on IX long and pointed; tube with straight sides, anal setae slightly shorter than tube.

Measurements (female from Queensland in microns). Body length 2200. Head, length 215; width behind eyes

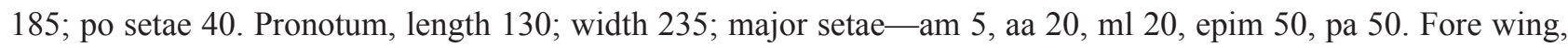
length 820 , width 75 ; sub-basal setae 20,25,30. Mesonotal lateral setae 20; metanotal median setae 15 . Tergite VI lateral setae 85 . Tergite IX setae 130, 150, 150. Tube length 160 . Antennal segments III-VIII length 55, 55, 50, 50, $40,40$.

Male macroptera. Similar to female but slightly smaller; tergite IX setae S2 short and weak.

Measurements (male from Queensland in microns). Body length 1750. Head length 185. Fore wing length 680. Tergite IX setae 130, 25, 170. Tube length 150 .

Specimens studied. New Caledonia, Rivier Bleu, 6 females, 6 males from rolled leaves of Pancheria alatanoides [Cunoniaceae], 7.iv.2012 (LAM5568); Mont Do, 2 females, 4 males from rolled apical leaves of Pancheria sp., 16.iv.2012 (LAM5606)(ANIC). Australia, Queensland: Brisbane Forest Park, Mt Nebo, 2 females, 1 male beaten from shrubs and ferns, 27.vii.1968 (LAM787)(ANIC); Lamington, O’Reilly's Moran Falls, 1 female by bark-spraying tree buttress, 4.viii.2013 (DJT1625)(QDPC).

Comments. This species has one of the posterolateral eye facets distinctly enlarged, as described in the original description of Thlibothrips. Presumably Bournier described the species originally in Athlibothrips because the mouth cone is relatively long, but that condition is not reliable as a generic distinction as it is commonly affected by cover-slip pressure in slide-mounted specimens. The pronotal setae of caledonensis vary in length, even among single population samples; the aa and epim setae vary from 15 to 25 and from 50 to 75 respectively in the sample 
listed from Rivier Bleue. Moreover, although specimens from New Caledonia have antennal segment IV yellowish brown, the specimens from Queensland have this segment almost as dark brown as the succeeding segments.

\section{Litotetothrips gallicola sp.n.}

(Figs 1, 4, 7)

Female macroptera. Body and legs brown, head darkest, fore tibiae paler, all tarsi brownish-yellow; antennal segment II yellow distally, III yellow, IV-VII yellow at base and variably light brown distally, VIII uniformly brown; fore wings weakly shaded but brown at base; major setae all pale. Head at least 1.3 times as long as wide (Fig. 1), widest across eyes, genae narrowed to base without setae; all eye facets equal in size; vertex irregularly transversely striate; stylets retracted about half-way to postocular setae; po setae weakly capitate. Antennal segment IV with 3 sense cones. Pronotum with a few sculpture lines at anterior and posterior, smooth medially; am setae varying, about half as long as aa setae; notopleural sutures complete; epim and pa setae long and capitate. Mesonotal lateral setae capitate; metanotal median setae small and acute (Fig. 4). Prosternal ferna as wide apart as their diameter; mesopresternum variably eroded, rarely slender and complete medially. Pelta elongate triangular; tergite lateral setae weakly capitate, setae on IX long and finely pointed; tube with straight sides, anal setae shorter than tube.

Measurements (holotype female in microns). Body length 2550. Head, length 250; width behind eyes 190; po

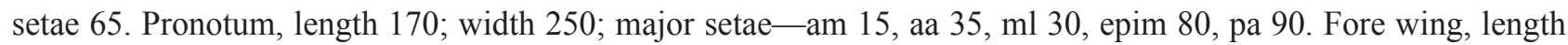
1000, width 90, 11 duplicated cilia; sub-basal setae 35, 50, 50. Mesonotal lateral setae 35; metanotal median setae 20. Tergite VI lateral setae 100. Tergite IX setae 210, 200, 180. Tube length 240. Antennal segments III-VIII length $60,65,55,55,50,50$.

Male macroptera. Similar to female but slightly smaller; tergite IX setae S2 short but varying in length and stoutness.

Measurements (paratype male in microns). Body length 2150. Head length 220. Fore wing length 800 . Tergite IX setae 200, 50, 200. Tube length 180 .

Specimens studied. Holotype female, Queensland, Brisbane Forest Park, Mt Nebo, from marginal leaf-roll galls on Elaeocarpus obovatus [Elaeocarpaceae], 9.vii.2002 (LAM4182) (in ANIC).

Paratypes: taken with holotype, 10 females, 6 males (in ANIC \& QDPC).

Comments. This species has the head and maxillary stylets in the form indicated in the generic diagnosis of Thlibothrips by Okajima (2006). However, that author indicated that Thlibothrips species were not associated with galls, whereas this new species was found in leaf-roll galls. Moreover, in contrast to the original diagnosis of Thlibothrips (Priesner 1952) there are no enlarged eye facets. It is particularly similar in structure to Okajima's description and illustrations of Thlibothrips antennalis from Honshu and the Izu Islands, Japan, but differs in having capitate major setae and a more elongate pelta.

\section{Litotetothrips tareei sp.n.}

(Figs 5, 8, 9)

Male macroptera. Body and legs brown, head and tube darkest, fore tibiae brownish yellow distally, fore tarsi yellow but mid and hind tarsi brown; antennal segment II yellow distally, III yellow, IV-V yellow on basal half, VI-VIII brown; fore wings brown at base, then a pale band followed by weak shading but with apical third paler with margins shaded; major setae on head and pronotum dark, all abdominal setae pale. Head scarcely longer than wide, widest just behind eyes, genae narrowed to basal neck without setae; vertex with irregular transverse sculpture lines; compound eyes without an enlarged posterolateral facet; stylets apparently retracted to postocular setae; po setae blunt at apex. Antennal segment IV with 3 sense cones. Pronotum with a few sculpture lines at anterior and posterior, smooth medially; am and aa setae blunt, almost half as long as epim setae; notopleural sutures complete; epim and pa setae weakly capitate. Mesonotal lateral setae small and blunt at apex; metanotal median setae small and acute. Prosternal ferna large, distance between them slightly less than their diameter (Fig. 9); mesopresternum transverse and fully developed. Fore wing with 10-13 duplicated cilia. Pelta broadly triangular, with paired campaniform sensilla (Fig. 5); tergite lateral setae blunt to weakly capitate; tergite IX setae S1 long and pointed, setae S2 short and stout; tube with straight sides, anal setae shorter than tube. 

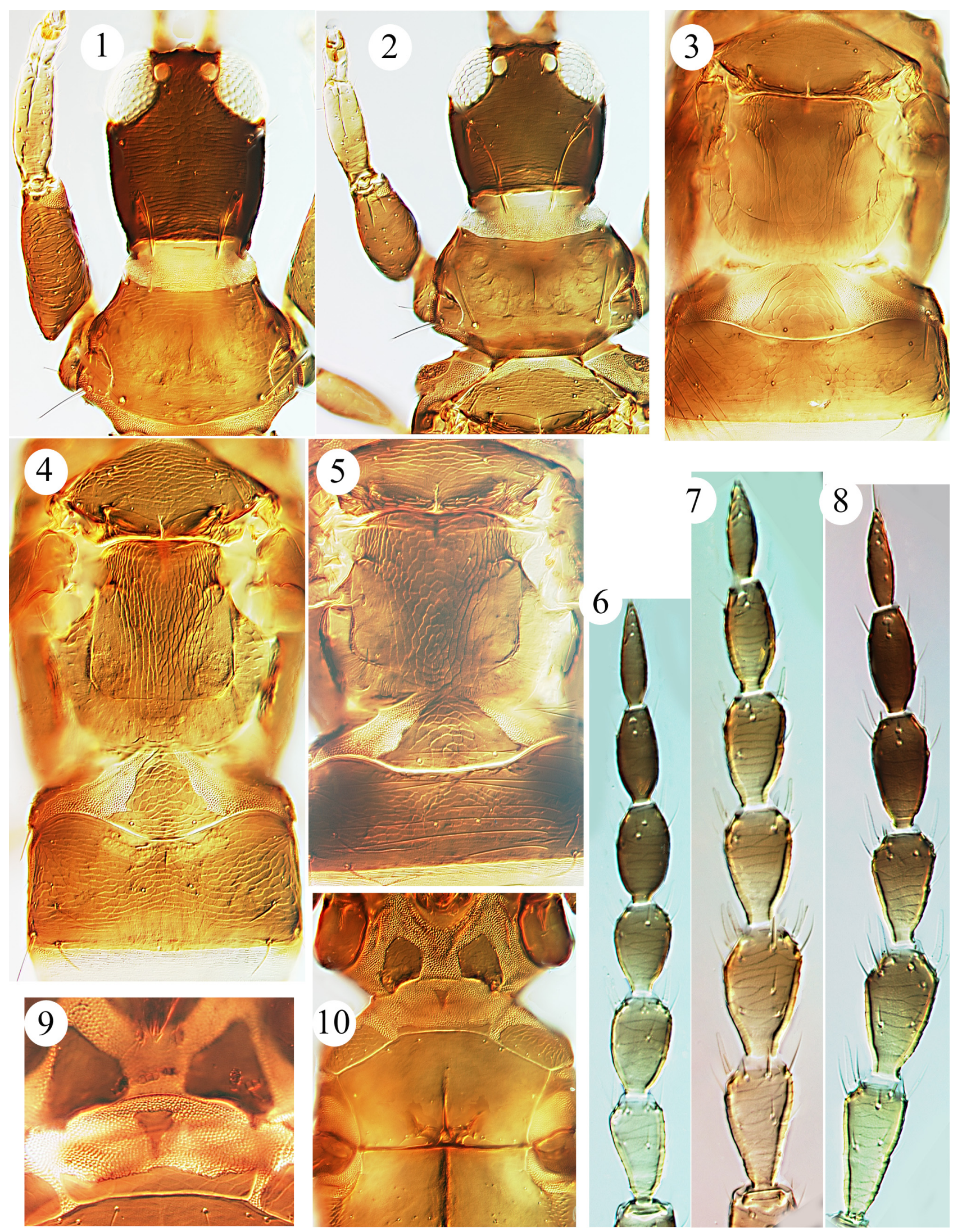

FIGURES 1-10. Litotetothrips species. Head \& pronotum 1-2: (1) gallicola; (2) caledonensis. Mesonotum to tergite II 3-5: (3) caledonensis; (4) gallicola; (5) tareei. Antenna 6-8: (6) caledonensis; (7) gallicola; (8) tareei. Thoracic sternites 9-10: (9) tareei; (10) caledonensis. 
Measurements (holotype male in microns). Body length 2150. Head, length 225; width behind eyes 200; po setae 40. Pronotum, length 150; width 250; major setae - am 20, aa 15, ml 30, epim 55, pa 40. Fore wing, length 850, width 85; sub-basal setae 30,30,35. Mesonotal lateral setae 25; metanotal median setae 15 . Tergite VI lateral setae 85 . Tergite IX setae 180, 35, 190. Tube length 210. Antennal segments III-VIII length 65, 70, 65, 60, 55, 45.

Female macroptera. Similar in colour and structure to male; antennal segments V-VI almost uniformly brown, and major setae on head and pronotum more clearly capitate.

Specimens studied. Holotype male, New South Wales, $3 \mathrm{~km}$ north of Lansdowne (near Taree), from an unknown tree, 21.xi.1990 (G. Williams) (ANIC).

Paratypes: same locality and collector as holotype, 1 male from Caldcluvia paniculosa, 13.xi.1990 (in ANIC); Queensland, Mt Glorious rainforest, 1 female from dead leaves, 1.viii.2012 (DJT1392) (in QDPC).

Comments. In the shape of the head and body this species is similar to caledonensis, but both sexes are considerably larger with unusually dark brown setae on the head and pronotum, the pronotal setae are more robust, the posterolateral eye facets are not larger than the other facets, and the distal third of the fore wings is paler than the median area.

\section{References}

Bournier, A. (1993) Thysanoptères gallicoles de Nouvelle-Calédonie. Bulletin de la Société entomologique de France, 98, $357-366$.

Dang, L.H., Mound, L.A. \& Qiao, G.X. (2014) Conspectus of the Phlaeothripinae genera from China and Southeast Asia (Thysanoptera, Phlaeothripidae). Zootaxa, 3807 (1), 001-082.

https://doi.org/10.11646/zootaxa.3807.1.1

Feng, J.N. \& Gou, F.Z. (2004) A new species of Litotetothrips (Thysanoptera: Phlaeothripidae) from China. Entomotaxonomia, $26(2), 104-106$.

Kudo, I. (1975) On the genus Litotetothrips Priesner (Thys. Phlaeothripidae), with the description of a new species. Kontyu, 43, $138-146$.

Kudo, I. (1994) Further notes on the genus Litotetothrips (Thysanoptera: Phlaeothripidae). Insecta Matsumurana, New Series, $50,53-78$.

Lindner, M.F., Ferrari, A., Mound, L.A. \& Cavalleri, A. (2018) Holopothrips diversity—a Neotropical genus of gall-inducing insects (Thysanoptera, Phlaeothripidae). Zootaxa, 4494 (1), 1-99. https://doi.org/10.11646/zootaxa.4494.1.1

Mound, L.A. (2008) Identification and host associations of some Thysanoptera Phlaeothripinae described from Australia pre1930. Zootaxa, 1714 (1), 41-60.

https://doi.org/10.11646/zootaxa.1714.1.5

Mound, L.A. \& Marullo, R. (1996) The Thrips of Central and South America: An Introduction. Memoirs on Entomology, International, 6, 1-488.

Mound, L.A. \& Tree, D.J. (2021a) Structural variation among species of Leeuwenia (Thysanoptera, Phlaeothripinae) with three new species from Australia. Zootaxa, 4903 (3), 439-447.

Mound, L.A. \& Tree, D.J. (2021b) Taxonomic problems with Gynaikothrips and related genera (Thysanoptera, Phlaeothripinae): the ficorum/uzeli complex and taxa endemic to Australia. Zootaxa, 5023 (4), 537-554. https://doi.org/10.11646/zootaxa.5023.4.4

Okajima, S. (1981) The genus Thlibothrips Priesner of leaf-rolling Phlaeothripidae (Thysanoptera). Transactions of the Shikoku entomological Society, 15, 141-150.

Okajima, S. (2006) The Suborder Tubulifera (Thysanoptera). The Insects of Japan, 2, 1-720. The Entomological Society of Japan, Touka Shobo Co. Ltd., Fukuoka.

Priesner, H. (1929) Indomalayische Thysanopteren I. Treubia, 10, 447-462.

Priesner, H. (1952) On some new genera and species of Thysanoptera from the Oriental region. Indian Journal of Entomology, $13,183-200$.

Reyes, C.P. (1994) Thysanoptera (Hexapoda) of the Philippine Islands. Raffles Bulletin of Zoology, 42 (2), 107-507.

ThripsWiki (2021) ThripsWiki-providing information on the World's thrips. Available from: http://thrips.info/wiki/ (accessed 8 July 2021) 